\title{
LOCKE, LEIBNIZ AND THE STATE SPACE*
}

\section{INTRODUCTION. THE STRANGE CASE OF PIERRE MENARD}

In 1934, we are told, ${ }^{1}$ the character of Pierre Menard, symbolist of Nîmes and author of several works in the field of history of philosophy, determines to embark on a task which is manifestly 'absurd'. Necessarily absurd, but - and Borges is insistent on this point - sufficiently justified. In a sense it is the relation of these two poles that concerns this note on the Leibnizian state space.

What is this absurdity to which Menard sets all his 'subterranean' endeavours? The preparation is everything: Menard will learn seventeenth century Spanish, re-embrace the Catholic faith, forget all European history from 1602 to 1918, be - not become mark but beMiguel de Cervantes. And then, Pierre Menard of Nîmes proposes, he will write Don Quixote.

It is in no way a question of copying out the text from memory, nor faithfully regurgitating its style and themes. In fact although Menard had read Don Quixote some years before, he will go out of his way to forget that experience, particularly the chapters that most struck him, and will focus his effort on the ninth, thirty-eighth and twenty-second chapters. Insofar as we consider any particular sentence of the work, there is absolutely no determination by the parallel sentence in the original. Nevertheless the end result will not be a possible Quixote, a simulacrum, or even an image accentuating that work. Rather, Menard's 'astonishing' goal is to produce, line for line, word for word, the exact Don Quixote.

\footnotetext{
* Stephen Connelly, PhD; Reader, University of Warwick. Contact: s.j.connelly@warwick.ac.uk. ${ }^{1}$ J-L Borges, 'Pierre Menard, autor del Quixote,' in Ficciones (Editorial Sur 1944). The short story has of course inspired several interpretations, focusing primarily on authorial intent, notably Roland Barthes, 'La Mort de l'auteur' in Image-Music-Text (Fontana Press 1977), and Michel Foucault, 'Qu'estce qu'un auteur?' (lecture of 22 February 1969 translated as 'What is an author?' by Donald F. Bouchard and Sherry Simon, in Donald F. Bouchard ed. Language, Counter-Memory, Practice (Blackwell 1977)).
} 
To achieve this feat he submits only to two 'polar' laws. First, he shall attempt subjective (formaliter) or psychological variation; the second law obliges him 'to sacrifice [variation] to the "original" text and irrefutably rationalise this annihilation'.

The result: Menard's text (at least its surviving fragments) is both one-to-one identical with the original, and yet an immeasurable improvement on it. What has changed of course is the world in which Menard's text is present, a world in which at the very least Cervantes' text is already present. Yet Menard tells us that he has written 'without tautology'.

There are three features here which I wish to extract from Borges' fictional obituary: (a) the absurdity of the undertaking; and (b) the two polar laws which, rather than any particular text, govern the writing: (i) the attempt of subjective variation; (ii) the obligation of objective elimination. I will spend the larger portion of my time on these two laws, before I turn to questions of absurdity.

Now having made this horizontal division between subject and object, I will be highlighting the relationship between subjective activity (in time) and objective space. I will be interested in the laws that generate that space and thereby paralleling Henri Lefebvre to some degree in speaking of absolute space and what he terms abstract and contradictory space. This will lead to a second, vertical division between what Leibniz calls the primary and the derivative, and what in certain modern contexts we would call the global and the local. The claim here will be that Menard's affirmation of the second, objective law - the ominously named law of justified annihilation - can be best understood not according to a theory of absolute space as found in Descartes and Locke, but according to a Leibnizian theory of global generative laws and local spaces. This allows Menard to avoid tautology even as he affirms absurdity. In order to attempt an explanation of this difference, I will briefly recount the one- 
sided 'debate' between Locke and Leibniz over space and power, before indicating the relevance of this work to Leibniz's thinking of obligations and the state space.

As such, to consider these polar laws will be to consider the nexus of law and space, of moral command and the constitution of extension. Indeed, too often we find one pole privileged over the other, with space being simply the passive receptacle of subjective activity. Locke provides an interesting case in point. Here, initial promise gives way to a dualism between an empirically constituted real subject, and a dead, preformed and monotonous object: space. As Étienne Balibar has shown, ${ }^{2}$ Locke's theory of personal identity is grounded in a new concept of consciousness in which the accretion of memory - experience - produces that consciousness. Experience does not presuppose consciousness; consciousness presupposes experience. On this view subjectivity is the 'felt' experience of the simpler ideas on the more complex - the subject - the simpler ideas being constitutive of it. Moreover, the causal agency of the subject is its own capacity to produce affect in another, thereby disclosing an interlocking order of the production of subjectivities. It is worth adding that each idea need not give its whole self to a subject, for were that so one could speak of a world consciousness. Rather, only parts are given; some aspect of an entity interacts with another as an experience, and forms that other's consciousness. This thesis - of elimination of the irrelevant - has the advantage of accounting for the passing away of a cause of experience without destroying the consciousnesses it has effected.

One might observe in this doctrine the methodology of our Pierre Menard, who seeks the experiences of Cervantes - the language, history, enmities - in order to be Cervantes as a subject. The full range of subjective variation is explored given a constant battle with Menard's

\footnotetext{
2 Étienne Balibar, Identity and Difference (Verso 2013).
} 
own experience of having read Don Quixote; a battle that is fought by sacrificing irrelevances to 'being the Cervantes that produces that work'. Menard's approach seems, on the side of authorial subjectivity, to be in principle sound. But he must also produce that work; that work must also be governed by the polar laws. This requires additional considerations with respect not to subject but object, relatively speaking. Menard knows that it is not enough that he be subjectively Cervantes; he must also produce a world in which Don Quixote as novel exists.

'But now we see the extent of this astonishing absurdity!' you might exclaim. 'It is one thing for our Nîmois to claim a subjective equivalence with Miguel de Cervantes, quite another to impose this on a world.' I would ask you to be patient: Menard's approach will illustrate just what is at stake when we speak of a world.

Now if we are to search for resources to understand this production of a world, of its extensive distribution just so-and-so, Locke disappoints us. Not for want of a theory of extension, but for having abandoned the theory of space that follows naturally from this doctrine of subjective consciousness. We know from Locke's Journal of June 1676 that of his own motion he had settled on a realist ${ }^{3}$ account of space. ${ }^{4}$ Just as consciousnesses are the result of the accretion of related experiences, so too space is a relation - 'distance' - which is only in the result of the respective simultaneity of two bodies. The bodies encounter each other and produce space between them in the result This suggests a thesis in which the subject is affected by the experience of this real relation as an objectification through presentation, to

\footnotetext{
3 I use realist in the Scholastic sense rather than the simple ' $x$ exists whether I think it or not' sense common today. By the latter definition Locke's absolute space is real; whereas Scholastics and Leibniz would have required some form of (usually final) causal explanation for the realisation of the space to regard it as real.

4 Locke's intellectual journey is documented by Geoffrey Gorham \& Edward Slowik, 'Locke and Newton on Space and Time and their Sensible Measures' in Z. Biener \& E. Schliesser eds. Newton and Empiricism (OUP, 2014) 119-37.
} 
use Whitehead's phrase. This is opposed to that subject's intensive memorial experience. We experience two incommensurable sets of ideas - the inside and the outside - and this incommensurability is possible just because consciousness is in the result of experience. The knower presupposes the knowledge.

Locke possesses these tools to construct an account of a world of real space, and so can perhaps aid our reading of the work of Pierre Menard. Yet he abandons this line of thought. The impetus seems to be a review he conducts of Newton's Principia in 1688 and Locke's erroneous if understandable conclusion that an absolute, fixed and empty space is the only respectable thesis. The result is twofold: (i) on the one hand an imbalance between an innovative theory of empirical subjectivity and a now objective but passive extension; and (ii) on the other a complete subordination of objectivity to the eternal rules of an absolute space. Whatever is produced by a subject must obey the timeless axioms of a dead receptacle and becomes lost in its indifference. The geometer, to use Aristotle's example, constructs a rectangle of determinate proportions, then a second of the same proportions. Do we have two individual rectangles or the one, for nothing geometric about these rectangles discloses their difference unless they are subsumed as part of a larger, single space which contains them, determining their respective differences as relative to their subordination within the same frame. They cease to be whole individuals but simply parts of the same space, itself subordinate to space as such. Lockean absolute space dooms Menard's project to tautology: to write word-for-word Don Quixote is to simply reproduce a congruent form, a pointless geometric repetition of the gnomon lacking all thisness (haecceitas), distanced from the original only by being part of a single, whole. This is not Menard's aim at all.

Our task is to reflect on what it would mean for an object to be a causal coincident in the production of the space of Menard's Don Quixote. What it means for the author to prepare not 
just himself but also the world for this literary feat, and how one might comprehend its feasibility.

\section{PART 1. LEIBNIZ'S REAL PRODUCTION OF SPACE}

Leibniz provides a route to the solution, though the solution is not itself Leibnizian. To trace this path we need not look to Leibniz's infamous engagement with the Newtonian school of absolute space. In the guise of Theophilus, he engages Philalethes as Locke in a discourse which turns on the question of power, and it is here that Leibniz's thinking is forcefully underscored. The notion of power (Leibniz correctly assumes Locke means potentia) is one of Locke's categorical inheritances which hinders as much as helps his philosophical efforts; but it provides a point of clear comparison with Leibniz's views. The framing here remains the relationship between a subject which is the cause of objects in the world, and the affects which that subject experiences as its world. Using the language of powers, ${ }^{5}$ Locke proposes an entirely one-sided division: the causal subject has the power to produce an effect in an object; the object has the power simply to receive that causality. There is no sense in which the objective world when abstracted from all active subjects is more than the eternal truths of space and time as a blank canvas. ${ }^{6}$

In response to this Leibniz's Theophilus sets out a theory of primary forces, with a notion of a primary activity or entelechy that corresponds to causal agency, operating through particular, derivative efforts. There follows a heavy 'reading' of the Lockean position which

\footnotetext{
5 In the sense of dúnamis that implies a capacity, rather than a potentiality.

6 'Time and space indicate possibilities beyond any that might be supposed to be actual. Time and space are of the nature of eternal truths, which equally concern the possible and the actual.' (Leibniz, New Essays on the Human Understanding, Peter Remnant \& Jonathan Bennett eds. (CUP, 2003) II.xiv s.26, 154 .
} 
arguably results in the latter's adoption of more familiar Scholastic terminology than that of Locke's consciousness and disquiet, but it can be taken as somewhat in the Lockean spirit. This is so, until Leibniz's Theophilus interjects:

There is, furthermore, a more special kind of passive power which carries more reality with it: it is a power which matter has, for matter has not only mobility (i.e. the capacity for or receptivity to movement) but also resistance, which includes both impenetrability and inertia. 7 Leibniz sets up a primary passive force which is opposed to that of subjectivity. Matter will not simply lend itself to causal agents but pushes back, so to speak.

Why? Why does the Leibnizian world push back? It is necessary to piece together the evidence, but the broad thesis seems to be this: corporeal movement and so change in the world is a derivative also of a primary passive force here identified with resistance. There must be a sufficient reason for this resistance, and this Leibniz locates in the claims of matter, driven by their existential deficiency in the face of a perfected God. ${ }^{8}$ The use of this 'claim' is not idle, for matter, indeed every possibility, makes an ethical claim or pretension to exist. One result, at this most basic physical level is that the mutual claims of matter inter se result in their mutual exclusivity in existence. Whereas distance for Locke is a function of relative position by reference to a third frame, distance for Leibniz is the result of possible matter repelling all that hinders its claim to existence thereby making the claim constitutive of a 'place'. Put another way, so as to underscore the morality at the heart of this conception, the Leibnizian

\footnotetext{
7 ibid.
}

${ }^{8}$ The classical doctrine found in Aristotle, Meta. Lambda 7; cf. Plotinus EnneadV.1; cf. Aquinas Summa Theologiae I ${ }^{\mathrm{a}} \mathrm{q} .44$ and also De Ente et Essentia. 
view $^{9}$ is in a long line of theories descending from John Duns Scotus at least, ${ }^{10}$ in which each real entity has a moral repugnance at the very notion that other real entities could simultaneously occupy its place, and this repugnance manifests as resistance and extensive distribution. In Leibnizian terms, the real entities are incompossible - two discernibly different entities cannot actually occupy the same space in the same world.

Observe then that the reality of this space depends not at all on the specific local distribution of matter, but rather on the imposition of a general law: co-locality is repugnant. This law is globally applicable because it follows from the relationship Leibniz assumes between primary matter and God, namely the claim to existence which is a power (potentia passiva) between God and creature. ${ }^{11}$

And so here I take issue with an element of Henri Lefebvre's account of Leibnizian space as indiscernible, only becoming a true space when occupied. In fact it is on the very issue of indiscernibility that Leibnizian space turns: two identical things are indiscernible, by the principle of that name, but the very difference of spatial extension is due to a moral claim by primary matter to its own place (opposed to all the others) and it is indeed this adherence to the law which is the topological condition differentiating the resultant space. This point is

\footnotetext{
9 On modal repugnance see my Leibniz: A Contribution to the Archaeology of Power (Edinburgh UP 2021) 278-80 and generally.

${ }^{10}$ Repugnance is weaker than logical impossibility in the sense that it is perfectly possible that Caesar crosses the Rubicon and he does not, but it is incompossible and so repugnant that he both have crossed and not crossed the Rubicon. See e.g. Jean-Pascal Anfray, 'Molina and Duns Scotus' in Aichele \& Kauffmann eds. A Companion to Luis de Molina (Brill 2014) 325-64.

${ }^{11}$ In De Potentia Aquinas struggles with the attribution of passive potency, because while it is a lack on the part of the creature, the lack is only predicable of the creature because God is present. This suggests the potency is really due to God, but Aquinas does not wish to predicate a kind of lack to God (following Aristotle) and so claims that when we say that God has power here it is a manner of speaking. His concern is perhaps also driven by an avoidance of the Plotinian alternative: that this power in creatures (the Minds and Souls) is really a spontaneous power in them (Ennead II.5).
} 
worth elucidating. Primary matter does not lay claim to a point in an existing space as its own; rather it claims to exist (existiturire ${ }^{2}$ ), and by virtue of that pretension to existence it constitutes its own place, from which a space is merely a result. The persistence of that claim is then manifested as a conatus ${ }^{13}$ to existing, or resistance, with respect to the claims of other matter. Accordingly, matter discerns itself by means of a claim on existence, brought under a global law.

\section{PART 2. INTERLUDE: DELEUZE ON THE COMMON SENSE OF INCOMPOSSIBILITY}

One might also notice the contrast to be drawn with Gilles Deleuze's Sixteenth Series of the Static Genesis, ${ }^{14}$ where, in its discussion of nonsense and Leibnizian incompossibility, Deleuze distinguishes between two kinds of nonsense. The first 'strong' kind is that field which preexists sense - that out of which sense is synthesised. The second is the nonsense that offends common sense within the classical philosophical canon, and this Deleuze identifies in the Sixteenth Series with incompossibility.

In a response to Edmund Husserl, Deleuze begins with mixtures of singularities and holds that series collect these into vicinities, the idea being that where series converge, there one has an individual (body). The constituent series are understood, after the Stoics, as verbal, and so it is said to be possible to unite these different vicinities into a world or environment (Umwelt) just where these verbs are equivalent in two given vicinities. The tree greens rather

\footnotetext{
12 A Leibnizian neologism using the future tense to mean something like 'Existence seeking'. See Couturat, Leibniz: Opuscules et fragments inédits de Leibniz (Félix Alcan 1903) 533; also Christophe Bouton, Time and Freedom (Northwestern UP 2014) 37.

${ }^{13}$ Leibniz's adopts and Hobbesian term at least by 1671 (see the fragment Trinitas. Mensin Gaston Grua, Leibniz: Textes inédites (Vrin 1948) 559).

14 Deleuze, Logique du sens, (Les Éditions de Minuit 1969) ' $16^{\mathrm{e}}$ série, de la genèse statique ontologique’.
} 
than is green, and equivalent events of just this act of greening are what we are looking for across worlds. Upon this first tier Deleuze builds a second in which he posits a transcendental unification constitutive of an EgO. ${ }^{15}$ This Ego is understood as a generative function with a variety of incompossible solutions, and which can be found across worlds which express these (the rose reddens here, the rose pink-ens there, but otherwise it is the same rose). Leibnizian 'nonsense' is engaged, Deleuze argues, because the Ego transcends the concord of compossibility, and unites the incompossible: Adam sins or does not sin depending on the world, but Adam cannot both sin and not sin in a single world. The concept or Ego of Adam englobes these incompossibilities.

My difficulty with this analysis is that it does not go far enough, privileging as it does the priority of an originary nonsense over that which Leibniz would regard as simply repugnant to common sense. In so doing Deleuze risks obscuring the similarity of his position with that of Leibniz and Husserl: ${ }^{16}$ it is possible that Adam sin and not $\sin$, though it is incompossible that they do both in the same world. Deleuze appears to wish to explain nonsense (in the weak sense) by permitting the Ego to occupy incompossible worlds, but the condition of this is that the subject already have determined its possibilities. It is possible for Adam to sin or not sin, just not simultaneously. What is nonsensical in this? Leibniz's concern is not in the result - a particular actualisation of a possibility - but in the generative rules which determine all the possibilities and, critically, subsume the impossibilities under the identity of the Ego. By explaining incompossibility according to the twin poles of Ego and

\footnotetext{
${ }_{15}$ The terminology here is directly addressed to Husserl's phenomenology, particularly during its Ideen $I$ phase in which Husserl pursues a pure phenomenology as a transcendental-phenomenological investigation of absolute consciousness. See e.g. Ideen zu einer reinen Phänomenologie und phänomenologischen Philosophie, I Buch (Niemayer 1913) 110-11.

${ }^{16}$ Cf. Ideen I163-5.
} 
many worlds, the impossibility (or nonsense) that only arises from the logic of possibility is tamed and explained away: the impossible is possible, just not in this world.

Deleuze would perhaps respond that this is indeed a limitation of weak nonsense (that which opposes common sense), thus further justifying his recourse to the 'strong' originary nonsense from which sense arises. My concern is that the approach in Logic of Sense closes off a third sense of nonsense which embraces the impossible that has as its condition the logical strictures of possibility, but rebels against them nevertheless.

\section{PART 3. LEIBNIZ'S STATE SPACE}

Now, returning to our main theme, the modern temptation would be to regard the nexus of moral repugnance and logical absurdity that frames the Leibnizian production of space as a Neoscholastic hangover, akin to the soon to be defunct sense of laws of nature as having truly been legislated for. Yet we need not look far to observe the structurally equivalent doctrine at work in Leibniz's legal treatises, notably the Elementa Iuris Naturalis ('Concept B' and 'Concept C' (1670-71)) which develop his so-called Iuris Modalia.

Leibniz's reading of Locke sets up a subject defined by a primary activity, which is the basis for a set of possible actions within its power. This grounds a consideration of modality, and in the Iuris Modalia a deontic modality. That which makes an individual this individual, its primary activity, is deemed necessary, and Leibniz says it is equitable for the good person to pursue such actions. The identification of necessity and philosophical equity may seem strange, but it follows from Leibniz's doctrine that the primary active force is a spontaneous substantial effort, much as equity is a spontaneous intervention in the order of positive law. It is a necessity in the sense of uncaused cause i.e. if the agent chooses to act it acts according to 
its concept. The primary active force is a substrate for the derivative forces, and Leibniz deems these capacities or faculties as being what is just for the good person to do.

Our interest though is the other side of the equation: not the subjective activity but the objective realm of extension. Remember that Leibniz has opposed Locke's mute capacities to be affected with a primary passive force rooted in moral repugnance: a horror, so to speak, that non-identical entities should occupy the same place. In the Iuris Modalia, Leibniz makes the moral aspect of this doctrine explicit by identifying the primary passive force with obligation: defined as what the good person is obligated to do or refrain from doing. I merely note here that from primary passive force derives the omissible, being that set of actions which are not integral to the exercise of the good person's powers, but rather may or may not be done as a coincident (symbebekon) of them in particular circumstances.

I claim that it is only by maintaining the contextual (contensional ${ }^{17}$ ) mapping between the doctrine of resistance and the doctrine of obligation that we are able to appreciate the full significance of the latter. The field of possible juridical actions is not a tabula rasa in which the subject exercises his powers as he sees fit, and just as importantly, nor is it an absolute space in which the same juridical actions are simply translatable to every possible situation. The local conditions in which one acts may vary and may or may not be determinative of the exercise of power by the subject. This variability of spaces of juridical action is permitted because the various local conditions are all subject to a governing primary obligation which has, one might say, a global effect i.e. it is present in every diverse locale.

Now in the context of the Iuris Modalia Leibniz informs us that the foremost 'global obligation' is that the individual act for the best, and Nicolas Rescher argues that this is to be

\footnotetext{
${ }^{17}$ Roughly, the mapping between two different methodologies, here the account of dynamics and the theory of deontic modality.
} 
understood as a positive counsel that one maximise reality through the expression of the greatest variety. But if we approach this same claim critically and in light of the doctrine of resistance, the notion of global obligation falls under a different light. To do this we take the reality maximisation principle identified by Rescher: ${ }^{18}$

If necessarily act $x$ is reality maximising, then it is equitable (necessary) that the good person do $x$,

and negate it:

If impossibly act $x$ is reality maximising, then it is prohibited (impossible) that the good person do $x$ (i.e. they are obligated not to do it).

Note that I have skipped a few logical steps in these statements, which are discussed in detail in my Leibniz.19

What is statement b. actually saying? Think back to the notion of repugnance, noting that it is grounded in logical moralisation. There the logical contrary of the principle of identity of indiscernibles was a principle of resistance: that discernibles are repulsed by co-location. This, I claim, is just what we are seeing in the above statements. The logical contrary of the equitable 'duty' to maximise reality is the obligation not to do that which is deemed morally repugnant, namely that which in no world maximises reality.

18 Nicolas Rescher, 'Contingentia Mundi: Leibniz on the World's Contingency' (2001) 33(2) Studia Leibnitiana 145-62.

19 Connelly, Leibniz: A Contribution to the Archaeology of Power (Edinburgh UP 2021). 


\section{PART 4. SOME CONSEQUENCES}

Of the consequences that follow I would like to highlight three.

First, this doctrine of juridical impossibility is a global law, applicable in a variety of local contexts. This allows Leibniz to develop a thesis of hypothetical necessity that attempts to ensure freedom of the will. Under a doctrine of absolute moral space it seems that what is obligatory is obligatory in the same way everywhere, both in terms of the obligation and the conditions within which that obligation is to be complied with. The consequence - compliance - is necessary in each case because the conditions are necessarily the same in every case. Leibniz holds, on the contrary, that it is not the consequence that is necessary, but rather only the consequent. For example, whether or not local conditions exact compliance with the obligation is entirely contingent, but if they are such as to exact compliance then the good person ought to comply. The key point here is the contingency of the local space. This separation of local and global determinations permits a freedom of action with respect to the contingency of particular conditions - the local moral space - while preserving the governance of certain principles deemed applicable to all moral spaces. Thus the best will be different depending on the conditions, and the conditions may be such where there are equally degree maximising options (as we see in Aquinas' account of Creation), but the best operates to incline in all these localities. Likewise, the morally absurd or repugnant is not a local contingency for Leibniz, but a global principle commanding what is intolerable in any possible world. The repugnant repels in all localities, though depending on the conditions no actual effect may be produced.

Second, it is worth remarking that this spatial understanding of legal obligations has its roots in Leibniz's time at the University of Leipzig where he, with Samuel von Pufendorf, studied under the Cartesian sympathiser Erhardt Weigel. It is from Weigel that Leibniz 
inherits $^{20}$ the notion of a 'state space'. Yet whereas for Weigel this space is the analytic and uniform normed space of Descartes - the space which is so useful to Newton and Locke - for Leibniz, under the influence of his theory of dynamical forces, it becomes subject to these two tiers of normalisation: the derivative local conditions and the primary global laws. This difference of levels permits variety in the number of state spaces, while ensuring their submission not to single absolute space but to certain objective principles ${ }^{21}$ which are present everywhere, inclining but, thanks to the hypotheticality of conditions, not necessitating in every case.

Third, we have an explanation for the astonishing task of Pierre Menard. We now see that it is in no way a criticism that we attribute absurdity of Menard's task to rewrite Don Quixote; it is a positive attribute of his endeavour. Indeed, it is revolutionary. Let me explain. We have accepted for the sake of argument that Menard can take on the subjective consciousness of Cervantes. As a premise he submits to a global law of annihilation, which aims at the same mischief as the indiscernibility principle. Being global the obligation allows local choice according to the local conditions: if Menard chooses then he must abide by the rule of annihilation to preserve a global consistency which he must rationalise. Menard's point is that it is necessary but not sufficient for him to be Cervantes, for Cervantes could have chosen locally to write a different Don Quixote, and then Menard would have to write that alternative Don Quixote. To write the best Don Quixote Menard is subject to the same global law but now in different objective local conditions. He too may choose to write a different Don Quixote, a better one - long live variety - but he writes in a world where Don Quixote already

\footnotetext{
${ }^{20}$ See e.g. reply 4 to Question XVI in Leibniz's early Specimen Quaestionum Philosophicarum discussed in Connelly, Leibniz (2021) 245-6.

${ }^{21}$ Sketched in e.g. the De calculo situum of 1715-1716, in Louis Couterat, Opuscules (1903) 548-556.
} 
exists and in which therefore the law of annihilation has an immediate content: there cannot be two indiscernible Don Quixotes in this world both because they would be the same Don Quixote and because the failure to vary would contradict the principle of reality maximisation. To state this in its moral form: to produce a second, repetitious Don Quixote is absurd (morally repugnant).

Yet it is an absurdity that our hero embraces. In producing this Don Quixote, Menard is engaging in a striking act of spatial sabotage - his Don Quixote is better not because it is different; it is the same - but because it exists in defiance of Leibnizian morality. As such the assault on Lockean absolute space is a mere waystation on the road to this besieging of a single, God-given principle. The global law that condemns the tautology is undermined by the absurd repetition. No revision or emendation of a possible Don Quixote could have achieved this; only its repugnant return at the hand of Menard.

What can we learn from Pierre Menard's bold experiment? Arguably it is this: that in Borges' fictional evocation of the absurd we have a sketch of what could be a quite precise endeavour, namely the positive exploration of those things which are deemed, according to the governance of a global law, to be absurd, nonsense, repugnant. Of course, the genealogy of the pathological is a long-established feature of critical legal studies (primarily in its theoretically-minded guise). What is interesting to me, however, is an examination of the global laws which generate absurdities, and the exploration of the variety of these laws. In breaking with Leibniz's law we observe two possibilities, or perhaps better virtualities: first, that the faculty of imagination is able to posit concepts which are impossible, and that this is not a weakness of the imagination, but its power; second, in turning our mind, for example, to the laws that generate spaces and validity, and in so doing being minded to posit also laws 
which if otherwise subject to a global obligation would be absurd, we can see a creative route to new orderings - to new global laws.

\section{BY WAY OF CONCLUSION: ON ALTERNATIVE SPACES OF TRUTH}

I close with an example of what I mean. Take for example a simple binary truth structure (yes/ no) which can be shown to govern or evaluate a given space. It is the classical logic of the kinds of topology Lefebvre criticizes; ${ }^{22}$ and akin to the generic truth of Badiou's Being and Event. ${ }^{23}$ According to such a truth structure, something is the case or it is not; a space is a subset of a body or it is not. Here there is no room for a middle ground, nor indeed for a becoming. Yet it is possible to craft a more complex, explicitly dialectical truth structure to govern our space which provides an evaluation of becoming. Here we not only evaluate states, but these are now deemed secondary to their becoming and annihilation. Something is or is not in a continuous sense, or it becomes or ceases to be. Moreover, it is possible to become, either truthfully or absurdly, according as the domain of truth is defined. For example, if subspaces $a$ and $b$ are both included within a space evaluated as true, then it is possible to move from $a$ to $b$ in two ways, either by passing entirely within the space of truth, or by leaving the space of truth and returning to it. This is what I mean about the reduced importance of states: $a$ and $b$ remain the same, but the event of passage to $b$ is now differentiated solely by reference to the movement taken to reach it: the route of common sense or the route of nonsense.

\footnotetext{
${ }^{22}$ See e.g. the 'Introduction' to The Production of Space (Blackwell, 1991).

23 Denoted by $x(+)$ and $x(-)$, see Alain Badiou, Being and Event, Oliver Feltham trans. (Continuum 2005) $335 f f$.
} 


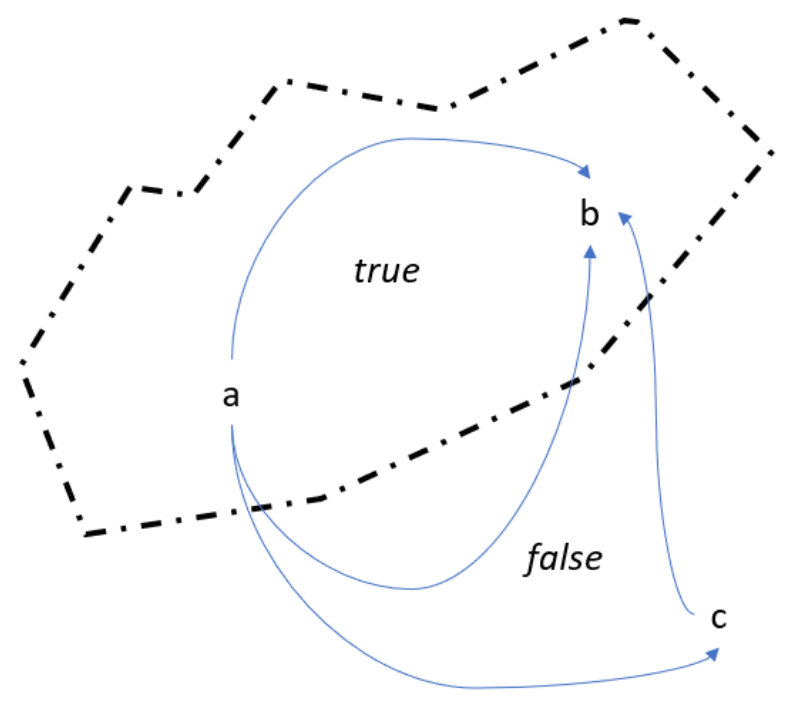

Figure 1. States a and $\mathrm{b}$ both are (subsets of true), whereas $\mathrm{c}$ is not (subset of false). If a and $b$ are the states of some entity in time, the construction indicates that the passage in time $a \rightarrow b$ may proceed either via truth or falsity, even at the limit (source: Author).

This example I think throws a final illumination on the strange case of Pierre Menard. It seems to me that in his journey from being Cervantes preparing to write Don Quixote to having completed Don Quixote just as it is, a task he sadly is unable to complete before his death, our classical regime of truth is at a loss to grasp what has happened. By observing that a dynamical movement is at play, and positing an alternative truth structure which can account for it, we now perhaps understand just what is at stake in Menard's creative act: it is neither what he has produced, nor who he is as producer which is critical; rather it is that he, unlike Cervantes, has taken the road of absurdity. 